\title{
MAPEAMENTO GEOMORFOLÓGICO DO MUNICÍPIO DE CAMPOS GERAIS, SUL DE MINAS GERAIS
}

\begin{abstract}
Alessandro Expedito Cabral
Mestre em Geografia pelo Programa de Pós-graduação em Geografia da Universidade Federal de Juiz de Fora alessandrocabral@ymail.com

Roberto Marques Neto

Professor do Departamento de Geociências e do Programa de Pós-graduação em Geografia da Universidade Federal de Juiz de Fora; professor colaborador do Programa de Pós-graduação em Geografia da Universidade

\begin{abstract}
RESUMO
O presente trabalho tem como objetivo divulgar os resultados alcançados através do mapeamento geomorfológico do município de Campos Gerais, localizado na microrregião de Varginha, no Sul do Estado de Minas Gerais, o qual se distribui em uma área de 769,504 $\mathrm{km}^{2}$. A elaboração da carta geomorfológica se procedeu amparada na metodologia proposta pelo Instituto Brasileiro de Geografia e Estatística. As bases cartográficas utilizadas consistem em imagens SRTM (Shuttle Radar Topography Mission) e cartas topográficas da área de estudo disponibilizadas pelo IBGE em escala de 1:50.000, a qual atendeu fielmente os objetivos propostos. O trabalho permitiu mapear as unidades geomorfológicas com padrões de formas semelhantes, compostas por modelados de agradação e dissecação, além de identificar fatos relevantes sobre a evolução do relevo por meio da interpretação dos dados morfométricos, e de processos atuantes sobre a superfície, como voçorocas, ravinas, capturas fluviais, etc. os quais foram representados por simbologia específica, permitindo uma interpretação mais minuciosa a respeito dos processos ocorrentes no sistema geomorfológico da área em questão.
\end{abstract}

Palavras-chave: Carta geomorfológica. Relevo. Dimensão interfluvial. Profundidade de dissecação.

\section{GEOMORPHOLOGICAL MAPPING OF THE MUNICIPALITY OF CAMPOS GERAIS, SUL DE MINAS GERAIS}

\begin{abstract}
This work aims to disseminate the results obtained through the geomorphological mapping of the municipality of Campos Gerais. This city is located in the Varginha microregion in the South of the State of Minas Gerais, which is distributed in an area of $769,504 \mathrm{~km}^{2}$. The elaboration of the geomorphological chart was supported by the methodology proposed by the Brazilian Institute of Geography and Statistics (IBGE). The cartographic bases used are SRTM (Shuttle Radar Topography Mission) images and topographical maps of the study area made available by the IBGE in a scale of $1: 50.000$, which faithfully fulfilled the proposed objectives. The work was able to map the geomorphological units with patterns of similar shapes, composed of models of pleasing and dissecting, besides identifying relevant facts about the evolution of the relief through the interpretation of the morphometric data, and of processes acting on the surface, as gullies, ravines, river catches, etc. which were represented by specific symbology, allowing a more detailed interpretation of the processes that occur in the geomorphological system of the area in question.
\end{abstract}

Keywords: Geomorphological chart. Relief. Interfluvial dimension. Depth of dissection.

\section{INTRODUÇÃO}

O modelado terrestre está sujeito a diversas alterações relacionadas aos processos que atuam sobre a superfície da Terra, seja através dos agentes climáticos originados do período Quaternário resultando nos modelados morfoesculturais atuais, ou das atividades de ordem tectônica, que estruturam as grandes unidades morfoestruturais da superfície terrestre. Independentemente de quais sejam esses

\begin{tabular}{llllll}
\hline Caminhos de Geografia & Uberlândia-MG & v. 21, n. 76 & Ago/2020 & p. 42-56 & Página 42
\end{tabular}


processos, a dinâmica e evolução da paisagem está diretamente relacionada aos processos gerais operantes na superfície da Terra. Nesse contexto, diversas propostas de mapeamento geomorfológico como a de Tricart (1965), Ab'Saber (1969), Projeto Radambrasil (1973 a 1983), Nunes, et al, (1994), Ross (1992), Ross e Moroz (1996), Marques Neto, et al, (2015), entre outros, são apresentadas com intuito de investigar os processos dinâmicos e evolutivos do relevo regional. Klimaszewski (1982, apud FLOREZANO, 2008) aponta que o primeiro conceito de mapeamento geomorfológico foi apresentado no ano de 1914, em forma de Atlas Morfológico, pelo Geomorfólogo alemão Otto Karl Siegfried Passarge.

As cartas geomorfológicas nem sempre são elaboradas de maneira semelhante, se diferenciando de autor para autor, que não raro utilizam critérios diferentes em sua elaboração. Florenzano (2008) aponta para mapas europeus, franceses, ex-checoslovacos e húngaros, elaborados a partir das unidades litológico-estruturais como elementos básicos. Em contrapartida, os poloneses, russos, romenos e alemães consideram a forma como unidade básica na interpretação do sistema geomorfológico. Diante desse cenário, no Brasil diversas cartas geomorfológicas foram elaboradas, em diferentes escalas e levando em consideração diferentes unidades taxo-corológicas.

Segundo Gatto et al (1983), o Projeto Radambrasil apresentou trabalhos no âmbito da cartografia geomorfológica embasados no princípio da taxonomia do relevo, através do agrupamento de subconjuntos constituídos de tipos de modelados, permitindo a identificação das unidades geomorfológicas e o agrupamento das mesmas, baseada em ordens de grandeza espacial e temporal. Por essa concepção, o primeiro táxon foi definido a partir dos domínios morfoestruturais, grandes conjuntos de formas de relevo que contém subdivisões, as quais representam o segundo táxon, designadas como regiões geomorfológicas. O terceiro táxon se refere às unidades geomorfológicas, com um arranjo de formas de relevo fisionomicamente semelhantes em seus tipos de modelados. Dentro desse estaria o quarto táxon, os tipos de modelado, definidos a partir dos processos morfogenéticos atuantes.

O IBGE também elaborou um mapeamento geomorfológico para o território brasileiro, em que os conceitos utilizados na proposta também adotam como princípio básico o ordenamento dos fatos geomorfológicos de acordo com uma classificação temporal e espacial. As informações concernentes à litologia, pedologia, clima e morfodinâmica são utilizadas para a individualização dos conjuntos de feições decorrentes de sua ordem de grandeza, identificados como Domínios Morfoestruturais, Regiões Geomorfológicas, Unidades Geomorfológicas, Modelados e Formas de Relevo Simbolizadas (NUNES, et al, 1984).

Ross (1992) propõe a análise geomorfológica da paisagem a partir da classificação taxonômica do relevo, apresentando uma proposta de cartografia geomorfológica com base na classificação do relevo segundo princípios de hierarquização, focando o seu significado morfogenético e as influências estruturais e esculturais do modelado. Segundo o autor, os trabalhos de Cailleux e Tricart, bem como de Mecerjakov, propunham algo semelhante à sua proposta, porém os mesmos não haviam conseguido alcançar os objetos que conduziram ao mapeamento geomorfológico. No mesmo desenvolvimento metodológico da cartografia geomorfológica, Ross e Moroz (1996) apresentam o mapeamento geomorfológico para o Estado de São Paulo na escala de 1.500.000, justificando que os mapas já existentes, elaborados pelo IPT e pelo Radambrasil, não abrangiam todo o Estado e não estavam plenamente disponíveis para toda comunidade científica. Os autores ainda apontam para a intenção de gerar um produto cartográfico até então inexistente para o Estado de São Paulo segundo a perspectiva metológica em apreço.

A escolha da escala a ser trabalhada, necessariamente, implica no grau de detalhamento do que será mapeado. Segundo Tricart (1965), escalas pequenas representam os fenômenos morfoestruturais. Já as escalas grandes são capazes de identificar até mesmo processos erosivos atuais, como voçorocas e outras feições de espacialidade pontual. Marques Neto et al. (2015) apresentam um mapeamento para o município de Lima Duarte na escala de 1:50.000, e segundo os autores, com essa escala de trabalho foi possível mapear as unidades geomorfológicas ordenadas em padrões de formas semelhantes, segundo os modelados de dissecação e agradação, além de feições morfológicas e

$\begin{array}{llllll}\text { Caminhos de Geografia } & \text { Uberlândia-MG } & \text { v. 21, n. 76 } & \text { Ago/2020 } & \text { p. 42-56 } & \text { Página } 43\end{array}$


processos atuais como escarpas de falha, ravinas, focos de arenização e capturas fluviais mediante o recurso gráfico dos símbolos, confeccionáveis em diferentes softwares de desenho e de geoprocessamento.

A partir do exposto, o presente trabalho assume o objetivo de adotar a cartografia geomorfológica para auxiliar na compreensão dos processos atuantes no município de Campos Gerais, e como esses estão ligados à gênese e à evolução do relevo regional. Espera-se que o produto final, a carta geomorfológica, possa ser inserido como material de suporte em um futuro planejamento socioambiental para o município.

\section{PROCEDIMENTOS METODOLÓGICOS}

A execução do trabalho foi amparada pela proposta aplicada por Nunes et al (1994), segundo a qual o mapeamento geomorfológico tem como princípio básico o ordenamento dos fatos geomorfológicos, de acordo com uma classificação temporal e espacial. Para a individualização destes conjuntos de feições podem ser considerados como planos de informações a litologia, a pedologia, o clima e a morfodinâmica. De acordo com a ordem decrescente de grandeza são identificados: os Domínios Morfoestruturais, os quais compreendem os maiores táxons na compartimentação do relevo; as Regiões Geomorfológicas, que representam os compartimentos inseridos nos conjuntos litomorfoestruturais que, sob a ação dos fatores climáticos lhes conferem características genéticas comuns, agrupando feições semelhantes; as Unidades Geomorfológicas definidas como um arranjo de formas altimétrica e fisionomicamente semelhantes em seus diversos tipos de modelados. Por fim, são definidos os Modelados e as Formas de Relevo Simbolizadas, abrangendo um conjunto de formas de relevo que apresentam definição geométrica similar, em função de uma gênese comum e dos processos morfogenéticos atuantes, resultando na recorrência dos materiais correlativos superficiais.

Os procedimentos técnicos ocorreram através do levantamento de material bibliográfico e cartográfico, procedendo-se assim na compilação das concepções e técnicas adotadas para a compartimentação do relevo e elaboração da carta geomorfológica. O material cartográfico utilizado consistiu nas cartas topográficas da área de estudo, em escala de 1:50.000, disponibilizadas pelo IBGE, correspondente às folhas Alfenas (SF-23-I-I-3), Boa Esperança (SF-23-I-I-2), Campos Gerais (SF-23-I-I-1) e Três Pontas (SF-23-I-I-4), além de imagens SRTM (Shuttle Radar Topography Mission), disponibilizadas pelo sítio eletrônico do Earth Explorer (https://earthexplorer.usgs.gov/).

O primeiro passo foi gerar as cartas de declividade e hipsometria para a área de estudos. A geração da carta de declividade foi executada pelo software ArcGis, tendo como base o limite do município disponibilizado pelo banco de dados do IBGE, o qual procedeu a um corte dessa área na imagem SRTM, processada através da ferramenta Extract by Masck, encontrada no ArcTollBox. O próximo passo foi submeter o arquivo a um procedimento a partir da ferramenta Slope, também localizada no ArcTollBox, e a partir do raster gerado foram definidas as cinco classes de intervalos $\left(0 \%\right.$ a $6 \%{ }^{\circ}, 6 \%$ a $15 \%, 15 \%$ a $30 \%, 30 \%$ a $45 \%$ e $>45 \%$ ). A carta hipsométrica do município de Campos Gerais foi elaborada também pelo software ArcGis, tendo como base a imagem SRTM utilizada na elaboração da declividade. O arquivo foi processado a partir da ferramenta Fill, localizada no ArcTollBox, após processamento do raster foram definidas as classes determinando intervalos de 50 metros para cada classe altimétrica, sendo os intervalos divididos em 10 classes.

O terceiro passo constituiu no mapeamento dos padrões de formas semelhantes, seguindo a proposta de Nunes et al, (1994), para a qual foi gerado um modelo de relevo sombreado através de dados SRTM, processados pelo ArcGis, através da ferramenta Hillshade localizada no ArcTollBox, a qual junto com os modelos de declividade e hipsometria auxiliaram na identificação dessas formas. Posteriormente a isso foram coletados os dados morfométricos (dimensão interfluvial e profundidade de dissecação), sendo obtidos através das cartas do IBGE retro citadas. A profundidade de dissecação foi mensurada com base no desnível altimétrico estabelecido entre os topos e o fundo de vale de referência, sendo que para a área apresentada foram realizadas coletas em 215 pontos diferentes espalhados pelas quatro cartas, que compõem o município. A dimensão interfluvial foi calculada medindo-se a distância

\begin{tabular}{llllll}
\hline Caminhos de Geografia & Uberlândia-MG & v. 21, n. 76 & Ago/2020 & p. 42-56 & Página 44
\end{tabular}


entre duas linhas de drenagem ou entre diferentes pontos de surgência hídrica (considerando-se a hierarquia discernível na escala trabalhada), também mensurada em 215 pontos. Tais valores foram organizados em um sistema binário mostrado a partir de uma matriz de dissecação, conforme Nunes et al. (1994).

O passo seguinte foi a compartimentação do relevo, sendo utilizados tanto as folhas topográficas agrupadas, como já mencionado anteriormente, como os dados SRTM. Foram definidos dez compartimentos, dois deles relacionados aos modelados de agradação recebendo a simbologia $A$ (planícies fluviais e planícies e terraços), e oito relacionados aos modelados de dissecação, que receberam a simbologia $\mathrm{D}$, para os modelados de dissecação (morros, morrotes e colinas) e DE para os modelados de dissecação em controle estrutural (cristas e colinas), em consonância a Nunes et al. (1994). Para classificação e compartimentação dos modelados se fez a adaptação da metodologia aplicada pelo IPT (1981), conforme mostra o quadro 1.

Quadro 1 - Critérios utilizados para compartimentação do relevo.

\begin{tabular}{|c|c|c|}
\hline $\begin{array}{c}\text { Conjunto de sistemas de } \\
\text { Relevo. }\end{array}$ & $\begin{array}{c}\text { Declividade Dominante das } \\
\text { vertentes. }\end{array}$ & Amplitudes Locais. \\
\hline Planícies e Terraços & $<6 \%$ & $<100 \mathrm{~m}$ \\
\hline Relevo colinoso & $0 \%$ a $15 \%$ & $100 \mathrm{~m}$ a $300 \mathrm{~m}$ \\
\hline $\begin{array}{c}\text { Relevo de morros com } \\
\text { Vertentes suavizadas }\end{array}$ & $0 \%$ a $15 \%$ & $<100 \mathrm{~m}$ \\
\hline Relevo de morrotes & $>15 \%$ & $100 \mathrm{~m}$ a $300 \mathrm{~m}$ \\
\hline Relevo de morros & $>15 \%$ & $<300 \mathrm{~m}$ \\
\hline Relevo montanhoso & $>30 \%$ & - \\
\hline
\end{tabular}

Fonte - Adaptado do IPT (1981).

A finalização da carta geomorfológica ocorre com a inserção dos símbolos, os quais representaram as feições do relevo mais difíceis de serem notadas devido à escala utilizada. Os símbolos apresentam as cristas estruturais escarpadas, em áreas de falhas, os vales estruturais, as anomalias de drenagem, as capturas fluviais, afloramentos rochosos, e os processos erosivos superficiais como voçorocas e ravinas. A simbologia utilizada para representação desses processos foi adaptada do Manual Técnico de Geomorfologia do IBGE (NUNES, 1994). A finalização foi executada através do software ArcGis, por meio do qual todas as informações foram agrupadas formando a Carta Geomorfológica do município de Campos Gerais.

Simultâneo a execução dos procedimentos cartográficos citados, foram realizados trabalhos de campo para melhor interpretação dos fatos geomorfológicos ocorrentes no município de Campos Gerais, e para correções de possíveis erros apresentados no produto inicial. Os compartimentos mapeados para área de estudos foram percorridos por vias locais e trilhas, onde esses apresentavam maiores dificuldades em seu aceso. As formas simbolizadas do relevo como voçorocas e ravinas foram georreferenciadas em campo e, depois, ajustadas devidamente na carta geomorfológica. Anomalias de drenagens e capturas fluviais também foram constatadas e apresentadas através de zoom na carta topográfica e comparadas com recortes de imagens do Google Earth. Os trabalhos de campo contaram com imagens aéreas da área de estudo, cartas topográficas, GPS e câmera fotográfica.

\section{O MUNICÍPIO DE CAMPOS GERAIS}

O município de Campos Gerais está inserido na porção Sul do Estado de Minas Gerais (Figura 1), pertencendo à microrregião de Varginha, distribuído em uma área de $769,504 \mathrm{~km}^{2}$, tendo suas

\begin{tabular}{llllll}
\hline Caminhos de Geografia & Uberlândia-MG & v. 21, n. 76 & Ago/2020 & p. 42-56 & Página 45
\end{tabular}


principais atividades ligadas à agropecuária, com destaque para a produção de café, seguido da pecuária, com gado de corte e de leite, algumas culturas temporárias, como: milho, feijão e, atualmente, a soja, de menor expressão para a economia local. O município tem como cidades limítrofes Alfenas, Boa Esperança, Campo do Meio, Fama, Paraguaçu, Santana da Vargem e Três Pontas, pertencendo com essas cidades, como Santana da Vargem, ao complexo de furnas (ALAGO, 2019). A principal rodovia que atende ao município é a BR-369, e segundo o DER - MG, a distância de Campos Gerais para os grandes centros nacionais é de $316 \mathrm{~km}$ até a capital mineira, $351 \mathrm{~km}$ até a cidade de São Paulo, $480 \mathrm{~km}$ até o Rio de Janeiro e $851 \mathrm{~km}$ de distância até Brasília.

Figura 1 - Localização do Município de Campos Gerais no Estado de Minas Gerais.

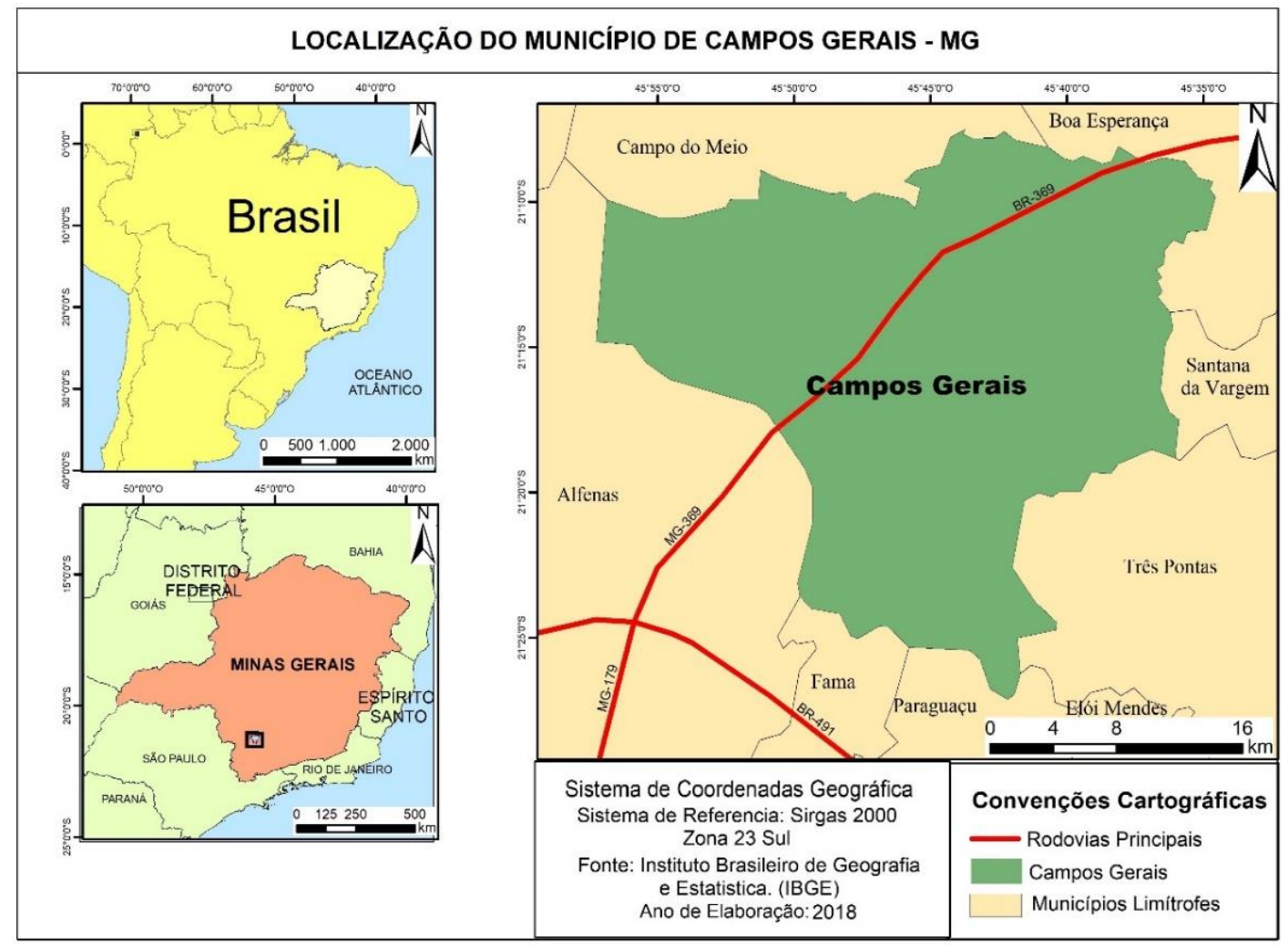

Fonte - Elaborado pelos autores (2019).

O município está localizado em uma região de clima tropical, com verões quentes e chuvosos e invernos mais secos com temperaturas mais amenas. Em escala regional tem seus dados climáticos obtidos pelas estações meteorológicas de Lavras, localiza a Leste de Campos Gerais, a cerca de $80 \mathrm{~km}$ em linha reta, e de Machado situada a Sudoeste do município, a cerca de $50 \mathrm{~km}$. Essas estações apontam para temperatura média e esta varia entre $18^{\circ} \mathrm{C}$ a $27^{\circ} \mathrm{C}$ (CAMPOS GERAIS, 2007). O município conta com uma estação meteorológica localizada em uma Unidade Avançada da Cooxupé em parceria coma Feagri-Nipe/Unicamp com apoio do GAS/Unesp-Jaboticabal e Embrapa/Informática para o monitoramento agrometeorológico e integração de dados em plataforma Web (SISMET), que trazem dados climáticos obtidos a partir do ano de 2012. Segundo o Sismet (2019), as temperaturas históricas mínimas chegam aos $18,3^{\circ}$ no mês de julho, e as máximas chegam a $24,5^{\circ}$ no mês de dezembro. As precipitações anuais chegam aos 1405,4 mm.

Do ponto de vista hidrográfico, o município de Campos Gerais está margeado em sua porção Sul e Oeste pelo Rio Sapucaí, afluente do Rio Grande, que devido à construção da Hidrelétrica de Furnas foi inundado nesse trecho, dando origem a Represa de Furnas. Em escala regional, o município está inserido na bacia do Rio Grande, pertencente à Bacia do Paraná. Segundo o IGAM (2013), o município de Campos Gerais está inserido na Unidade de Planejamento e Gestão dos Recursos Hídricos

$\begin{array}{llllll}\text { Caminhos de Geografia } & \text { Uberlândia-MG } & \text { v. 21, n. 76 } & \text { Ago/2020 } & \text { p. 42-56 } & \text { Página } 46\end{array}$


(UPGRH) GD3, na Região Central da bacia do Rio Grande. Em se tratando de aspectos locais, o município tem como principais redes de drenagem o Ribeirão da Onça, Ribeirão do Cervo, Ribeirão São Pedro, o Córrego da Divisa, o Córrego do Galo e Córrego do Barreirinho. O Ribeirão do Cervo, ao receber as águas do Córrego da Divisa, se destaca como o principal eixo de drenagem local, e assim como grande parte da rede de drenagem do município desagua na Represa de Furnas, esse é utilizado para o abastecimento da rede urbana do município, tendo a Serra do Macuco a Norte e a Serra da Fortaleza a Sul como limites de sua bacia, e também como os principais divisores de água do município (Figura 2).

Figura 2 - Organização da rede hidrográfica no município de Campos Gerais (MG).

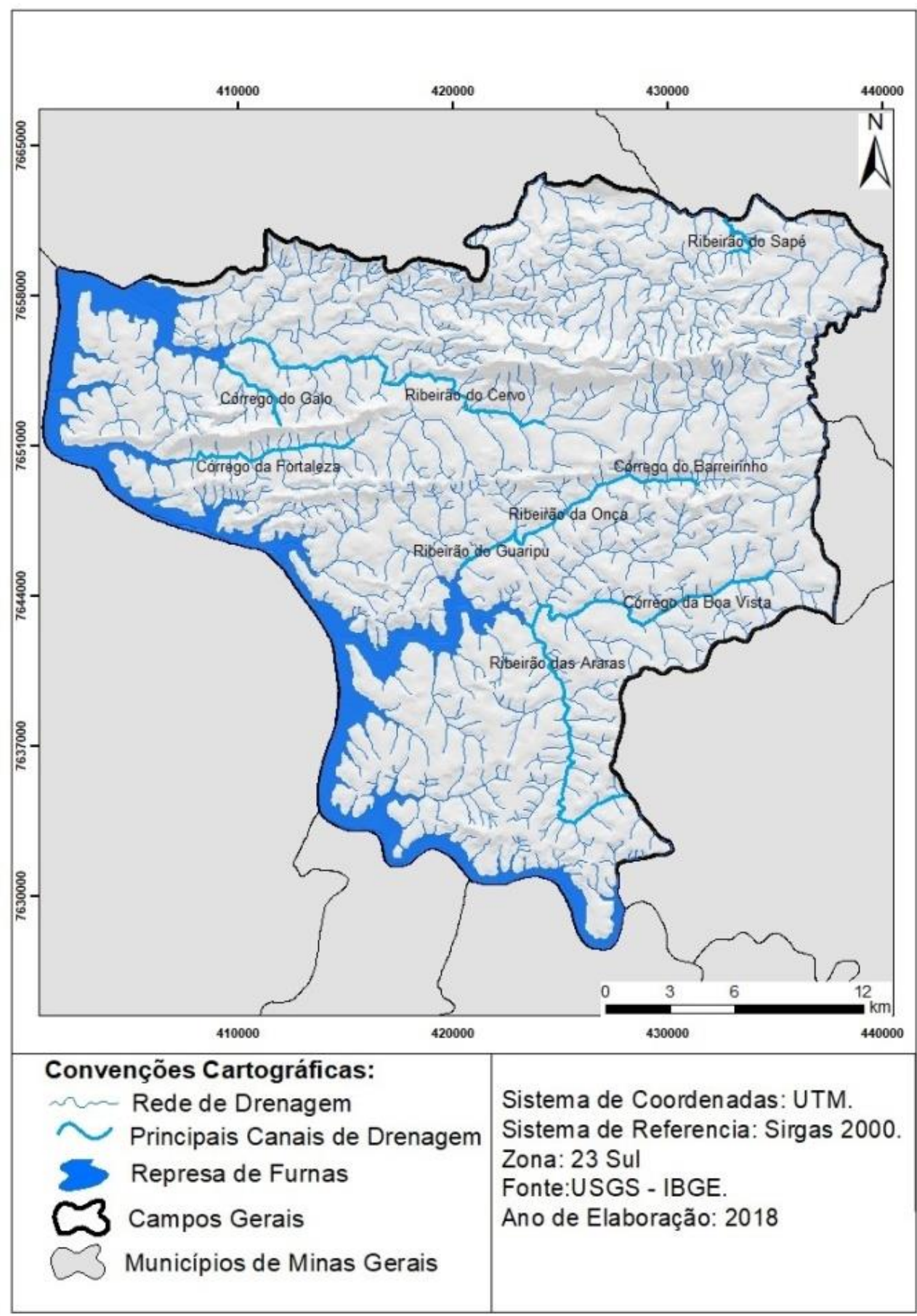

Fonte - Elaborado pelos autores (2019). 
O município de Campos Gerais está posicionado na borda Sul do Craton do São Francisco. Segundo Mattos (1986), a geologia regional é caracterizada, do ponto de vista das estruturas tectônicas, por falhamentos de empurrão, dobramentos e zonas de cisalhamentos rúpteis representadas por sistemas de falhas transcorrentes, com movimentação sinistral e direção predominante N60-70W. Esses cisalhamentos sofrem influência do cinturão de cisalhamento Campo do Meio (MORALES e HASUI, 1993). Segundo Campos (2012), as rochas que compõem a geologia do município pertencem à Unidade Arantina, composta por biotita muscovita, xistos e quartzitos em fácies anfibolito, à Unidade Paraiso, com predomínio de gnaisses e quartzitos, aos embasamentos dos Ortognaisses Campos Gerais, compostos por granitos e tonalitos, aos Ortognaisses Gaspar Lopes, com presença de granitos, aos Ortognaisses São Vicente, além de biotita gnaisses com intercalações de quartzitos e filitos, correspondendo à Megassequência Andrelândia. O quadro geomorfológico regional é aderente ao Planalto de Varginha (GATTO et al, 1983) ou Planalto Sul de Minas (alto Rio Grande) o qual, juntamente com o conjunto de serras, faz parte do Planalto Atlântico do Sudeste (AB'SABER, 1975) ou dos "Mares de Morros" (AB'SABER, 2003). Seu relevo apresenta altas cristas escarpadas alinhadas em sentido EW, com vertentes íngremes e declividade ocorrendo entre $15 \%$ e $45 \%$, chegando a até mais de $45 \%$ em alguns pontos, com vales largos e bem evoluídos, além de morrarias e colinas com formas mamelonares, topos aguçados, arredondados e planos com encostas suavizadas, interrompidos pelas cristas estruturais e por amplas planícies e terraços embutidos.

Os solos do município de Campos Gerais estabelecem relações estreitas com o relevo. Nas áreas mais elevadas, como nas cristas estruturais, há o predomínio de Argissolos com textura média a argilosa, com aparecimento de Cambissolos com a atenuação do declive. Nas áreas de relevo um pouco mais suavizadas, como nas morrarias e as nas colinas, dominam a pedogênese latossólica e nos fundos de vale se consorciam os Neossolos Flúvicos e faixas de hidromorfismo com ocorrência bem marcada de Gleissolos. A cobertura superficial da paisagem é marcada pela ocorrência de transição entre os biomas do Cerrado e da Mata Atlântica, intercalando a presença de matas fechadas com vegetação rasteira e estratos arbóreos espalhados. Segundo o IBGE (2012), o município possui uma cobertura vegetal predominante de mata secundária, com Floresta Estacional Semidecidual com fisionomia de Cerrado. Devido às atividades agropecuárias desenvolvidas, o município apresenta grande diversidade em sua composição vegetal, em que as áreas recobertas de matas foram dando lugar para as pastagens, as culturas temporárias e as lavouras de café.

\section{APRESENTAÇÃO E DISCUSSÃO DOS RESULTADOS}

\section{A carta geomorfológica e o sistema geomorfológico de Campos Gerais}

A carta geomorfológica gerada para o município de Campos Gerais mostra estreita relação dos modelados mapeados com a declividade (Figura 3) e a hipsometria (Figura 4) do terreno. Nas áreas de declividades mais suaves, entre $0 \%$ a $6 \%$, são encontradas as planícies, os terraços e as colinas. Esses modelados também estão associados às altitudes mais baixas na faixa de 780 metros às margens da represa de Furnas, e não ultrapassam os 900 metros, possuindo amplitudes de no máximo 100 metros. No caso das colinas, essas estão localizadas em áreas onde a declividade pode chegar a $15 \%$. Acima dos $15 \%$, e com amplitudes que oscilam entre 100 e 300 metros, e com até pouco mais de 1000 metros de altitude estão localizados os morros e morrotes, organizados em formas mais individualizadas, porém distribuídos em todos os setores do município. As áreas de maior declividade, altitude e amplitude estão concentradas mais na parte central e no Setor Norte do município, no qual se destaca a Serra da Onça e do Mato Dentro, com altitudes por volta de 1000 metros, e declividades entre $15 \%$ e $45 \%$, e as Serras da Fortaleza e do Paraíso, sendo que a primeira delas apresenta altitudes que chegam aos 1080 metros, e a segunda mencionada a 1280 metros. Nessas duas áreas, a declividade oscila entre os $15 \%$ e $45 \%$, porém apresentam declividades ainda superiores em alguns pontos específicos.

Figura 3 - Carta de declividade do município de Campos Gerais. 


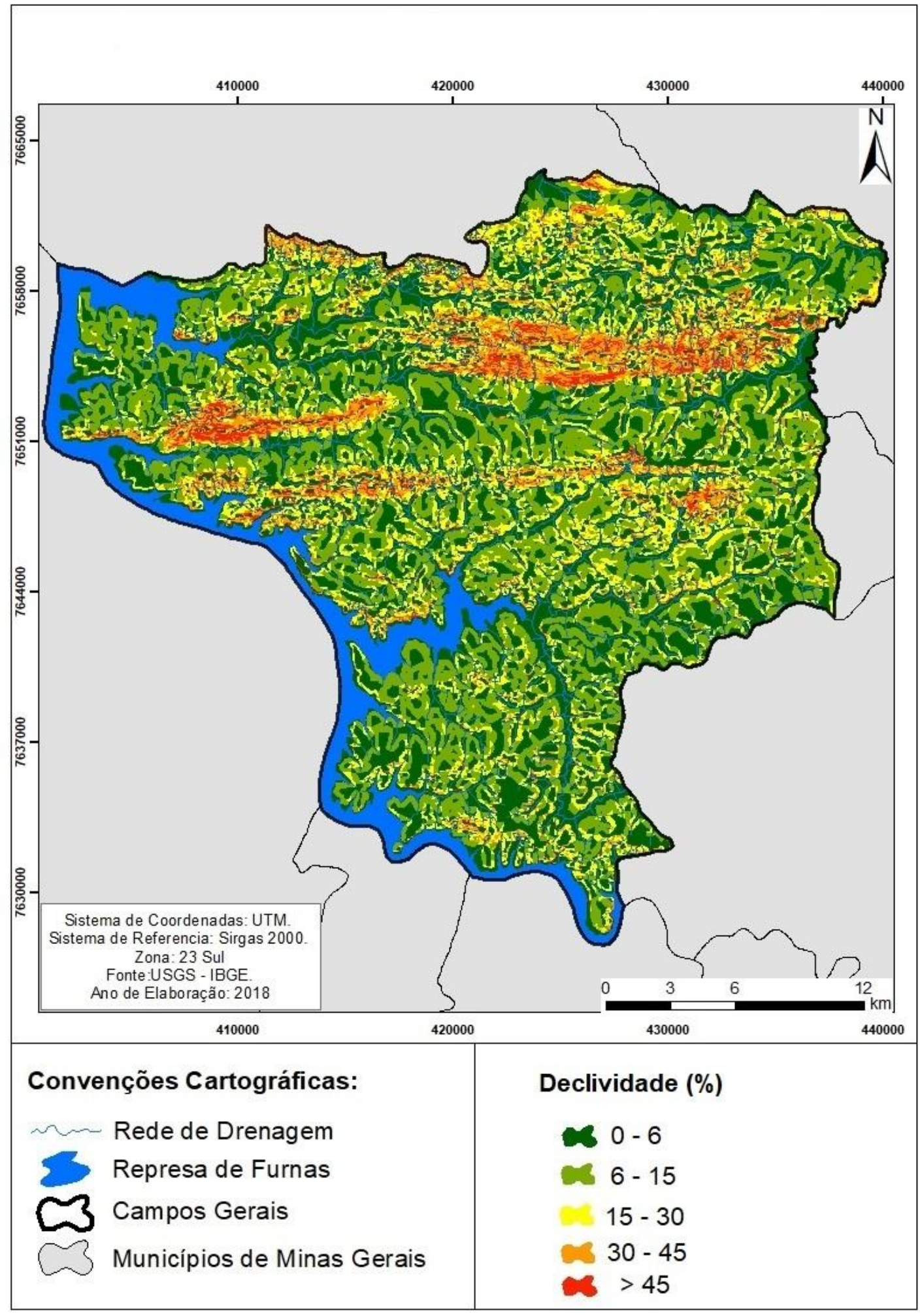

Fonte - Elaborado pelos autores (2019).

Figura 4 - Carta hipsométrica do município de Campos Gerais. 


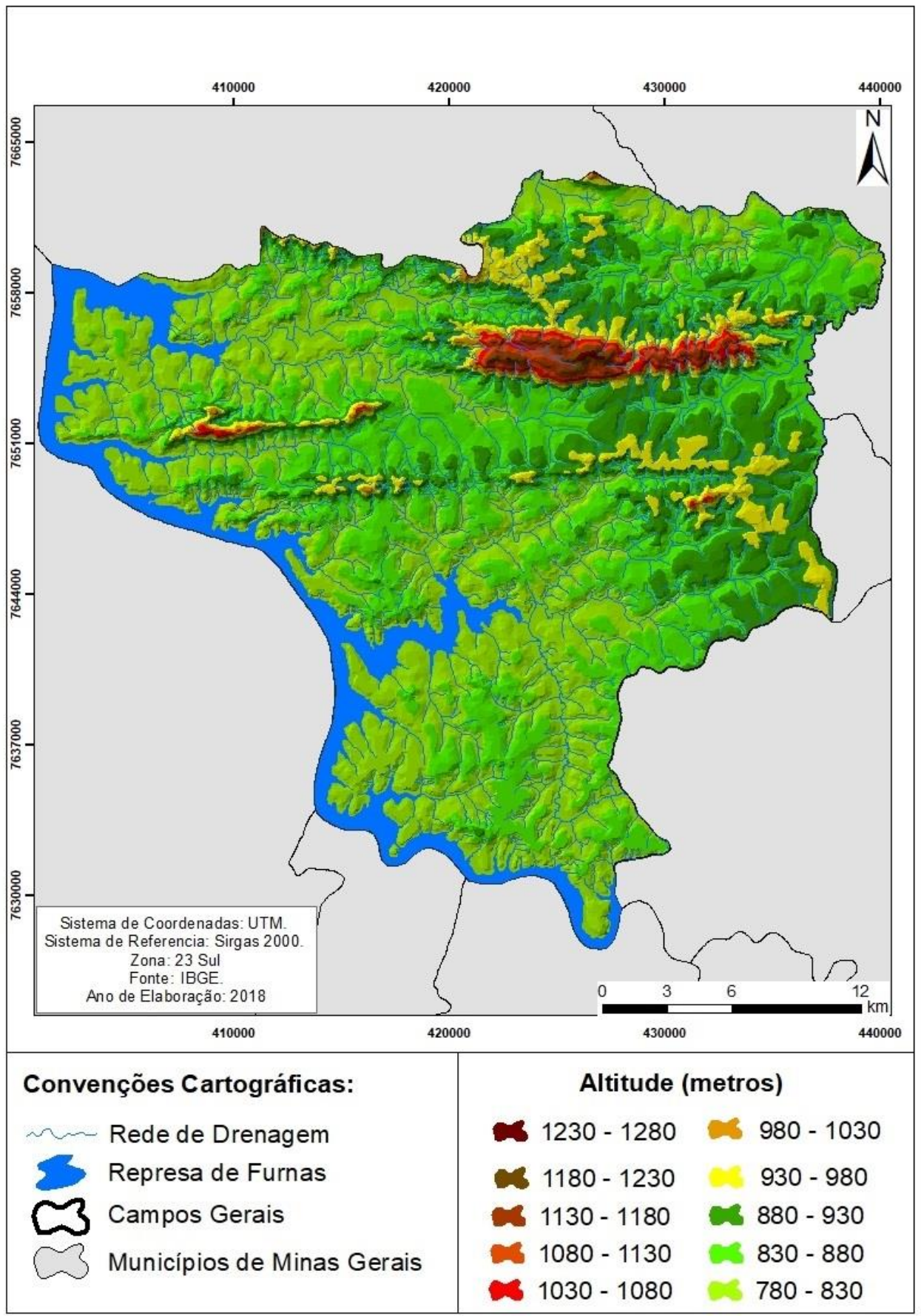

Fonte - Elaborado pelos autores (2019).

Com a elaboração da carta geomorfológica para o município de Campos Gerais (Figura 5) foram mapeados os seguintes tipos genéticos: Modelados de Agradação $(A)$, correspondente às planícies fluviais (Apf) e às planícies fluviais e terraços (Apft); Modelados de Dissecação Homogênea (D), corresponde às colinas (Dco), os patamares reafeiçoados em morrotes (Dpm), os morrotes (Dmr) e os Morros (Dm); Modelados de Dissecação em Controle Estrutural (DE), representados pelas colinas estruturais (DEco), pelos Patamares Reafeiçoados (DEpr), pelas Cristas Escarpadas em Controle Estrutural Rebaixadas (DEcr) e pelas Cristas Escarpadas em Controle Estrutural (DEce). Esses modelados foram individualizados.

O agrupamento das formas do relevo da área de estudo correspondente aos Modelados de Dissecação apresenta um compartimento altimontano bem definido pelas cristas escarpadas sustentadas por
Caminhos de Geografia
Uberlândia-MG
v. 21, n. 76
Ago/2020
p. $42-56$
Página 50 
litologias quartzíticas e gnáissicas em área de cisalhamento e forte controle estrutural, com amplitude local superior a 300 metros, apresentando maior altitude e declividade em relação aos outros modelados mapeados para o município. Os terrenos intermontanos são tipificados em morros e morrotes que apresentam morfologias mamelonares com topos mais arredondados e aguçados, com profundidade de dissecação inferior a 100 metros e declividade acima dos $15 \%$, sustentados por litologia gnáissico-graníticas. As colinas apresentam dissecação homogênea e em controle estrutural, compreendendo a geoformas com topos planos, declividade suave e amplitudes inferiores a 100 metros, sendo mapeadas sobre litologia gnáissico-granítica. Já os Modelados de Agradação são representados pelas planícies fluviais e terraços, os quais foram mapeados, principalmente, no entorno das colinas, apresentando dimensões distintas dependo de seu local de ocorrência, e marcando a passagem dos processos erosivos para os agradacionais.

Para fins de melhor visualização e apresentação das informações da carta geomorfológica, a legenda (Figura 6) foi apresentada em uma figura à parte, devido à grande quantidade de informações apresentadas por essa. A seguir serão apresentadas e discutidas as características principais de cada compartimento mapeado.

Figura 5 - Carta geomorfológica do município de Campos Gerais.

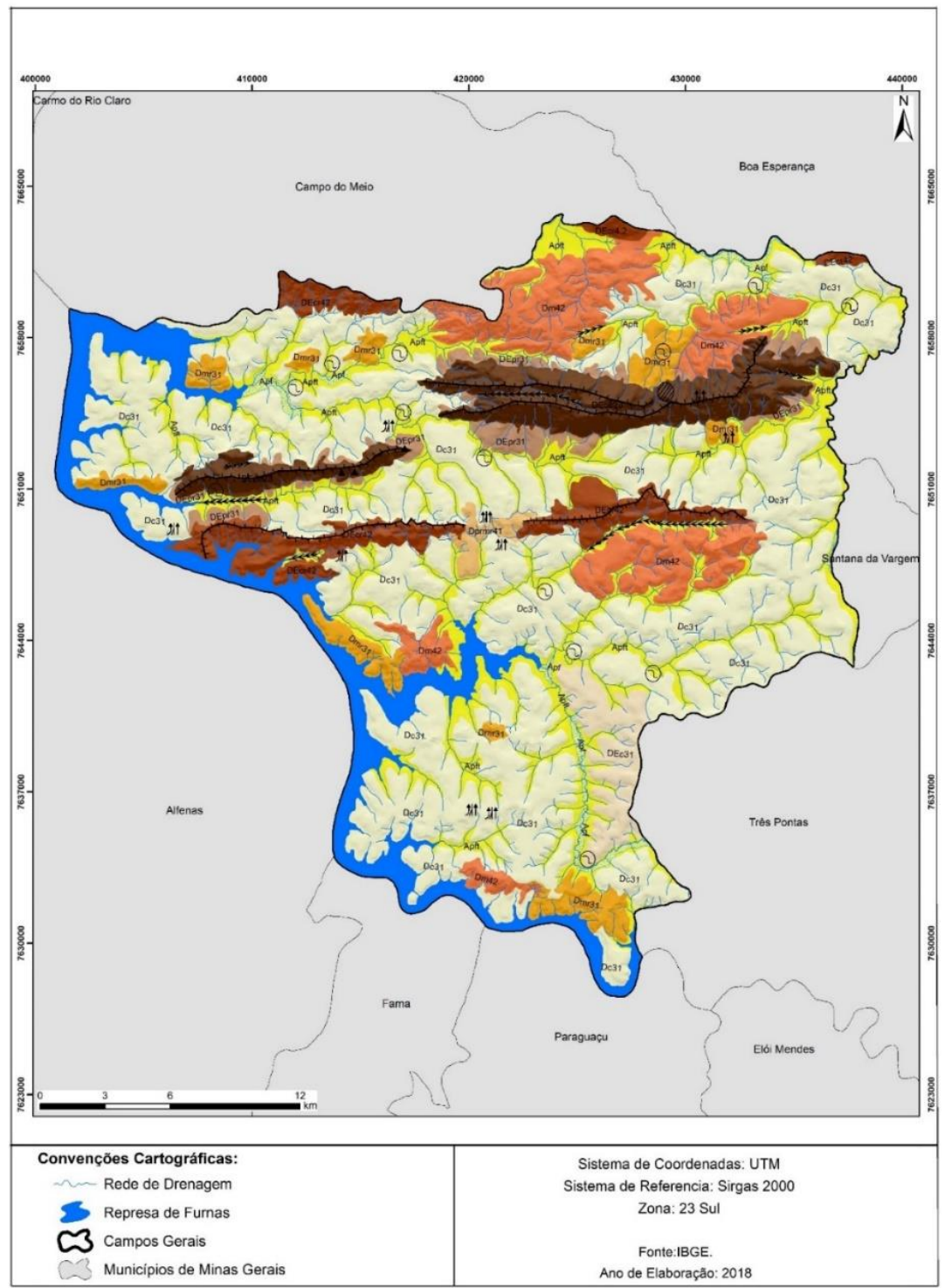

Fonte - Elaborado pelos autores (2019). 
Figura 6 - Legenda da carta geomorfológica do município de Campos Gerais.

MA: MODELLADOS DE AGRADAÇÃO.

Planicies Fluviais (Apf): Área plana resultante de acumulação fluvial sujeita a inundações periódicas, correspondendo às várzeas atuais. Ocorre nos vales com preenchimento aluvial.

Planícies e terraços (Apft): Áreas planas resultantes de acumulação fluvial, periodicamente alagadas, comportando meandros abandonados e cordões arenosos. Ocorrem nos vales com preenchimento aluvial, contendo material fi no a grosseiro, pleistocênico e holocênico.

MD: MODELADOS DE DISSECAÇÃO HOMOGÊNEA.

Colinas (Dco): Morfolofias mamelonares com topos convexos alongados e planos, com vertentes retiçineas e declividade suave. Patamares reafeiçoados em morrotes (Dpm): Patamares de relevo reafeiçoados pela dissecaçẩo dando origem a modelados como morfologia semelhantes aos morrotes.

Morrotes (Dmr): Morfologia mamelonáres rebaixadas com vertentes ingrimes e topos aguçados.

Morros (Dm): Morfologias mamelonáres em formas arredendadas ou alongadas, com topos alongados, convexos ou aguçados.

MDE: MODELADOS DE DISSECAÇÃO EM CONTROLE ESTRUTURAL.

Colinas estruturais (DEco): Morfolofias mamelonares sobre influência de controle estrutural, com topos convexos alongados e planos, com vertentes retiçineas e declividade suave.

Patamares Reafeiçoados (DEpr): Patamares de relevo com declividades mais suaves, reafeiçoados pelo intenso processo de dissecação fluvial,

Cristas escarpadas em controle estrutural rebaixadas (DEcr): Serras rebaixadas e alongadas, alinhadas em controle estrutural com declividades altas e vertentes escarpadas.

Cristas escarpas em controle estrutural (DEce): Serras alongadas alinhdas em controle estrutural com amplitide e declividade altas e vertentes escarpadas.

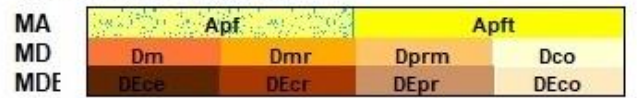

MORFOMETRIA DOS MODELADOS DE DISSECAÇÄO

\begin{tabular}{|l|c|c|c|c|c|}
\hline $\begin{array}{l}\text { Intensidade de } \\
\text { entalhe vertical da } \\
\text { drenagem }\end{array}$ & $\begin{array}{c}\text { Muito } \\
\text { Fina } \\
(<400)\end{array}$ & $\begin{array}{c}\text { Fina } \\
(\text { de } 401 \text { a } \\
600 \mathrm{~m})\end{array}$ & $\begin{array}{c}\text { Média } \\
(\mathrm{de} 601 \mathrm{a} \\
800 \mathrm{~m})\end{array}$ & $\begin{array}{c}\text { Grosseira } \\
(\mathrm{de} 801 \mathrm{a} \\
1000 \mathrm{~m})\end{array}$ & $\begin{array}{c}\text { Muito } \\
\text { Grosseira } \\
(>1000 \\
\mathrm{m})\end{array}$ \\
\hline Muito Fraca (<100 m) & 5.1 & 4.1 & 3.1 & 2.1 & 1.1 \\
\hline $\begin{array}{l}\text { Fraca (de 101 a 200 } \\
\mathrm{m})\end{array}$ & 5.2 & 4.2 & 3.2 & 2.2 & 1.2 \\
\hline $\begin{array}{l}\text { Mediana (de 201 a 500 } \\
\text { m) }\end{array}$ & 5.3 & 4.3 & 3.3 & 2.3 & 1.3 \\
\hline $\begin{array}{l}\text { Forte (de 501 a 1000 } \\
\text { m) }\end{array}$ & 5.4 & 4.4 & 3.4 & 2.4 & 1.4 \\
\hline Muito Forte (> 1000 m) & 5.5 & 4.5 & 3.5 & 2.5 & 1.5 \\
\hline
\end{tabular}

Fonte - Elaborado pelos autores (2019).

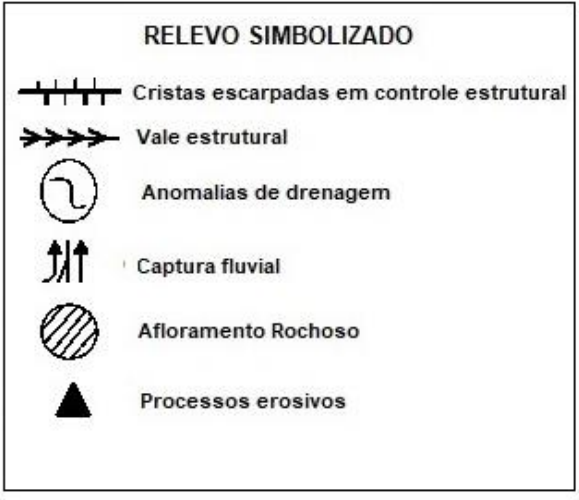

que que compreendem as porções de menor altitude e com declividades menores que $6 \%$, e estão localizados às margens dos principais troncos coletores do município. As planícies fluviais apresentam dimensões distintas e em inundação periódica, e foram mapeadas em quatro locais distintos na área de estudo. No Setor Noroeste do município, esse modelado foi encontrado em duas áreas próximas às margens do Ribeirão do Cervo, o qual nasce na Serra do Macuco e deságua na Represa de Furnas e em seu afluente, o Ribeirão Água Verde, que também nasce na Serra do Macuco. Nessa localidade, as planícies fluviais apresentam grandes dimensões, com algumas anomalias de drenagem no percurso dos córregos. No Setor Nordeste as planícies fluviais estão situadas às margens do Ribeirão do Sapé, que também nasce na Serra do Macuco e deságua na Represa de Furnas, porém no município de Campo do Meio, essa região é marcada por um modelado que apresenta grandes dimensões territoriais se expandindo para o município de Boa Esperança, no qual possui uma rede de drenagem dendrítica e algumas anomalias de drenagem.

Na porção Sudeste do município também foram mapeadas formas de planícies fluviais, alinhadas às margens do Ribeirão das Araras. Essas, em específico, possuem dimensões menores e apresentam drenagens com padrão treliça com significativa ocorrência de anomalias (Figura 7). As planícies e os terraços apresentam significativa abrangência espacial no município de Campos Gerais, sendo encontrados entre os limites das colinas, das morrarias e das cristas mais altas. Esses modelados apresentam um controle estrutural E-W na bacia do Córrego da Fortaleza, tendo a Serra da Fortaleza a sua margem direita e a Serra do Mato dentro a sua margem esquerda. Na área drenada pelo Córrego da Boa Vista também se apresenta um alinhamento estrutural NE-SO. Nos dois locais citados, a

\begin{tabular}{llllll}
\hline Caminhos de Geografia & Uberlândia-MG & v. 21, n. 76 & Ago/2020 & p. 42-56 & Página 52
\end{tabular}


drenagem se apresenta em forma de treliça, e há ocorrência de anomalias de drenagem. Nas demais áreas do município, essas planícies e terraços se apresentam sem orientação estrutural definida, com drenagem dendrítica e pouca ocorrência de anomalias.

Correspondendo a maior parte do município de Campos Gerais, as colinas homogeneamente dissecadas, apresentando declives suaves e baixas amplitudes, apresentando coberturas de alterações bem desenvolvidas. Essas colinas se apresentam como geoformas onduladas com topos planos e arredondados, contando com dimensões interfluviais médias e entalhe vertical muito fraco, com ocorrências de capturas fluviais (Figura 7). No Setor Nordeste do município se apresentam entrelaçadas entre a Serra do Paraíso e aos morros recobertos por plantações de café. Nas demais áreas se apresentam em grandes compartimentos entre a Represa de Furnas, os terraços e os morrotes. O fator declividade e a boa formação dos solos favorecem as atividades econômicas do local, principalmente, agricultura e pecuária, em que as pastagens e as lavouras de café dominam na paisagem e sobre as coberturas superficiais desses modelados. No Setor Sudeste da área de estudo foi mapeada uma forma de colinas apresentando controle estrutural definido pelo Ribeirão das Araras, com topos mais alinhados e planos e interflúvios lineares, com dimensões interfluviais médias e entalhe vertical muito fraco.

Na porção central do município foram mapeados os patamares reafeiçoados em morrotes, localizados entre a Serra da Onça e do Mato Dentro. Essa forma de relevo possui altimetria mais baixa em relação às Serras citadas anteriormente, pois apresenta uma forma de relevo ondulado, com dimensões interfluviais finas e entalhe vertical muito fraco, rede de drenagem dendrítica e alguns pontos de capturas fluviais.

A partir de amplitudes inferiores a 100 metros, porém com declividades acima de $15 \%$, foram mapeados os morrotes. O modelado em apreço apresenta vertentes mais curtas com dimensão interfluvial média, com entalhe vertical muito fraco, padrão de drenagem dendrítico e topos aguçados. O Setor Noroeste do município possui formas menores, limitadas pela Represa de Furnas e pelas planícies e terraços. Na porção Nordeste do município esse conjunto de formas é encontrado em duas localidades, a Norte da Serra do Paraíso, onde as geoformas são maiores, rodeadas pela própria serra, morros e colinas, e a Sul, apresentando formas menores bordejadas por colinas e pela Serra do Paraíso. No extremo Sul do município aparece rodeado por colinas, por planícies bem desenvolvidas e pela Represa de Furnas. Devido aos declives significativos, esses modelados ainda não sofreram interferência antrópica em toda sua área, principalmente nas partes mais próximas aos topos, nas quais ainda é possível encontrar cobertura vegetal nativa.

Com amplitudes superiores aos morrotes e declividade entre $15 \%$ e $30 \%$, os morros foram mapeados com maior ocorrência no Setor Norte, Nordeste e Centro-Leste do município de Campos Gerais. Esses modelados ostentam grandes formas mamelonares, com topos arredondados e pouco aguçados em algumas localidades. Possuem um padrão de drenagem dendrítica, em sua maioria, com dimensões interfluviais finas e entalhe vertical fraco, com topos aguçados e arredondados e vertentes mais extensas em relação aos morrotes. Na porção Centro-Leste do município, a Sul da Serra da Onça, um desses morros exibe drenagem em forma de treliça, havendo capturas fluviais e vales estruturais formados pelo processo de erosão.

Uma forma de modelado de dissecação em controle estrutural mapeado para o município de Campos Gerais corresponde aos patamares reafeiçoados em interflúvio local, encontrados no sopé das Serras do Mato Dentro, da Fortaleza, do Paraíso. Tais modelados se apresentaram em degraus em relação ao relevo ao seu redor, possuem altitudes que variam dos 860 a 900 metros, e declividades mais suavizadas. Apresenta dimensões interfluviais médias e entalhe vertical muito fraco. Por não possuírem uma declividade tão acentuada como a das cristas que ladeiam esses modelados, o uso da terra tem sido destinado para as pastagens e lavouras de café, havendo pequena quantidade de vegetação nativa em alguns canais que os dissecam.

Compondo parte importante das formas estruturais do relevo de Campos Gerais, foram mapeadas as cristas estruturais rebaixadas, localizadas na porção central da área de estudo. Essas cristas apresentam uma orientação $\mathrm{E}-\mathrm{W}$, quase que de uma extremidade a outra do município. Possuem amplitude próxima aos 200 metros, e declividades superiores a $30 \%$, seu relevo é dissecado pela drenagem com padrão dendrítico e treliça, exibindo dimensões interfluviais finas e entalhe vertical fraco, com formação de vales estruturais estabelecendo os limites com conjunto de morros a Sul. Esses modelados também foram encontrados no Setor Norte do município, porém com continuidade para os territórios municipais de Boa Esperança e Campo do Meio.

$\begin{array}{llllll}\text { Caminhos de Geografia } & \text { Uberlândia-MG } & \text { v. 21, n. 76 } & \text { Ago/2020 } & \text { p. 42-56 } & \text { Página } 53\end{array}$


Os modelados de maior altitude e declividade da área de estudo correspondem às cristas escarpadas em controle estrutural, em se tratando das Serras da Fortaleza e do Paraíso. A primeira delas consiste em uma crista francamente escarpada alinhada no sentido E-W, com altitudes máximas de 1080 metros, e características marcantes sobre a formação do relevo. Sua parte Norte apresenta drenagem com padrão dendrítico, enquanto a parte Sul apresenta uma rede de drenagem em treliça, constituída pelo Córrego da Fortaleza, o qual nasce na mesma Serra, em altitudes próximas aos 1000 metros, e deságua na Represa de Furnas. O local se destaca pela grande ocorrência de processos erosivos como ravinamento e voçorocamento (Figura 7), estando em pleno desenvolvimento. A Serra do Paraíso se apresenta em um grande corpo estrutural, com altitude máxima de 1280 metros, drenagem dendrítica na sua porção Norte e Sul, e treliça em uma parte de seu seguimento, em que é dividida em duas partes por um vale estrutural com altitudes que chegam aos 1000 metros. Nessa crista estão localizadas as principais nascentes do Ribeirão do Cervo, um dos principais eixos de drenagem do município, inclusive utilizado para coleta de água para o abastecimento da cidade. Nesse modelado também foram encontrados afloramentos rochosos de biotita gnaisse cinza, apresentada em porções finas de rochas alinhadas na mesma direção do modelado (E-W). Esses modelados apresentam declividades entre $15 \%$ e $45 \%$, tendo pontos que superam $45 \%$, e ostentam dimensões interfluviais medianas e entalhe vertical grosseiro, sendo os dois principais divisores de água do município.

Figura 7 - Visualização de algumas feições representadas por simbologias específicas. A) Capturas fluviais; B) Erosão por voçorocamento; C) Anomalias de drenagem.

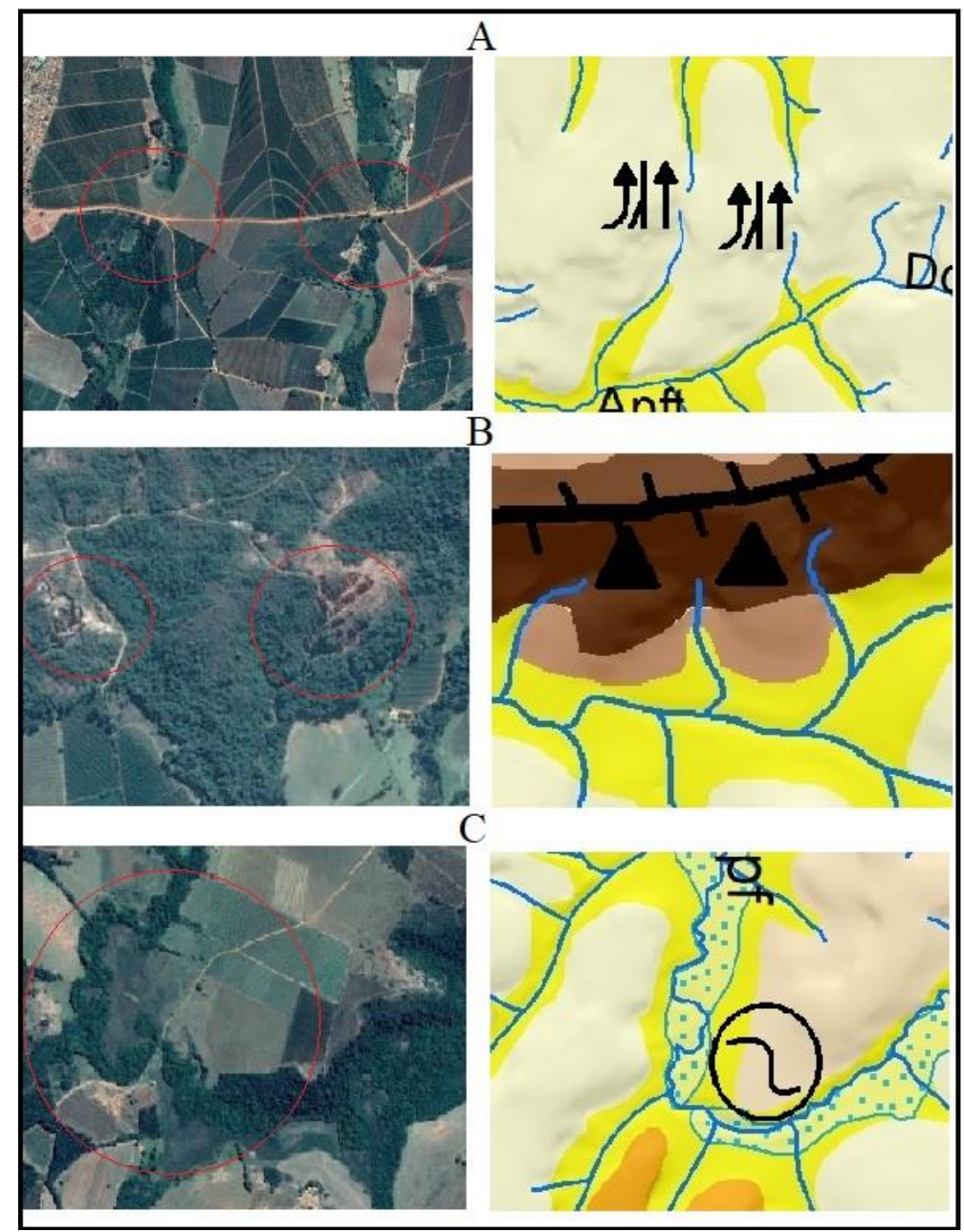

Fonte - Elaborado pelos autores (2019).

As principais formas de relevo mapeadas na área de estudo apresentam relações diretas com elementos estruturais e morfométricos. As cristas quartzíticas escarpadas estão localizadas em áreas

$\begin{array}{llllll}\text { Caminhos de Geografia } & \text { Uberlândia-MG } & \text { v. 21, n. 76 } & \text { Ago/2020 } & \text { p. 42-56 } & \text { Página } 54\end{array}$


de falhas da zona do cinturão de cisalhamento de Campo do Meio (MORALES e HASUI, 1993), e figuram como as superfícies de cimeira regionais, ocorrendo também em outras cristas alongadas e tabuliformes que tipificam o relevo na região do rio Grande margeando a represa de Furnas, importante nível de base regional que controla os processos erosivos nessa altura do vale. Os relevos mamelonizados em morros e colinas consubstanciam outra superfície, de caráter intermontando e recoberta por coberturas intemperizadas mais espessas, e que se encontram francamente dissecadas pela drenagem que abre as planícies fluviais ativas. Essa configuração, dada por cristas estruturais como superfícies de cimeira truncando terrenos intermontanos formados por relevos mamelonares, constitui uma tipicidade fundamental do relevo regional que eclode entre as cristas do Planalto do Alto Rio Grande, a Serra da Canastra e o domo vulcânico de Poços de Caldas.

\section{CONSIDERAÇÕES FINAIS}

O presente trabalho mostra a eficácia da cartografia geomorfológica na interpretação e classificação das formas do relevo, em que é possível mapear desde as formas correspondentes às grandes estruturas, até os processos morfodinâmicos atuantes sobre cada modelado, como: ravinas, voçorocas, capturas fluviais e demais processos que podem ser observados em escalas mais detalhadas. A escala de 1:50.000 utilizada no mapa, juntamente com a aplicação dos índices binários obtidos através da coleta de dados morfométricos, associados à inserção de símbolos alfanuméricos e demais simbologias, atenderam as necessidades propostas, permitindo a interpretação das organizações geomorfológicas nos diferentes níveis taxonômicos apresentados no mapa. Os índices morfométricos mostram que as cristas escarpadas apresentam maior energia e potencial morfodinâmico, fato comprovado em campo, pois os processos erosivos que ocorrem se concentram em maior frequência nesses modelados em relação aos demais.

Além do mapeamento dos padrões de formas semelhantes agrupados em modelados de agradação e dissecação, também foi possível mapear elementos morfoestruturais e morfodinâmicos ocorrentes, como anomalias apresentadas pela rede de drenagem e capturas fluviais que mudam a direção da rede de drenagem, provocando novas adaptações às formas de relevo, bem como vales estruturais encaixados entre cristas escarpadas, afloramentos rochosos, ravinas e voçorocas, sendo essa última um dos principais problemas relacionados com a perda de solos no município. Esses processos estão relacionados aos níveis taxonômicos mais detalhados e são possíveis de serem mapeados utilizandose de símbolos, plotados a partir de pontos georreferenciados em campo ou detectados por sensoriamento remoto.

A cartografia geomorfológica aplicada ao município de Campos Gerais se mostrou eficiente no entendimento da configuração do relevo local em seus processos estruturais e morfogenéticos, bem como permitiu algumas correlações com o relevo regional. Com a escala utilizada foi possível mapear e identificar processos dinâmicos associados às mudanças superficiais da paisagem, aos quais cabem discussões mais detalhadas. Espera-se que o material cartográfico elaborado possa servir de apoio aos órgãos responsáveis para o desenvolvimento de políticas socioambientais e outras ações voltadas à gestão territorial.

\section{AGRADECIMENTOS}

Ao Programa de Pós-Graduação em Geografia da Universidade Federal de Juiz de Fora e pela CAPES pela bolsa concedida durante a realização das pesquisas.

\section{REFERÊNCIAS}

AB'SABER, A. N. Formas de Relevo: texto básico. São Paulo: EDART, 1975. 80p. Os domínios da natureza no Brasil: potencialidades paisagísticas.

São Paulo: Ateliê Editorial, 2003 159p. https://doi.org/10.11606/issn.2316-9133.v11i11p7-8

Um conceito de geomorfologia a serviço de pesquisas sobre o quaternário.

Geomorfologia, v. 18, 1969, p.01-20.

\begin{tabular}{lllll}
\hline Caminhos de Geografia & Uberlândia-MG & v. 21, n. 76 & Ago/2020 & p. 42-56
\end{tabular}


ALKMIM, F.F. de. O que faz de um cráton um cráton? O cráton do São Francisco e as revelações almeidianas ao delimitá-lo. In: Mantesso-Neto, V. et al. (ed.) Geologia do Continente Sul-Americano: Evolução da Obra de Fernando Flávio Marques de Almeida. p. 17-34, São Paulo. Beca, 2004. 647p.

ASSOCIAÇÃO DOS MUNICÍPIOS DO LAGO DE FURNAS. ALAGO. Disponível em: http://www.alago.org.br/default.asp, acessado em janeiro de 2019.

CABRAL, A. E. Estudo geotécnico e ambiental da voçoroca da Serra da Fortaleza em Campos Gerais, sul de Minas Gerais. Trabalho de Conclusão de Curso. Instituto de Ciências da Natureza. Curso de Geografia. Universidade Federal de Alfenas, Alfenas. 2013.

CAMPOS, M. T. R. Mapeamento Geológico 1:100.000 da região de Alfenas, sul de Minas Gerais. Trabalho de Conclusão de Curso (Bacharelado em Geologia) - Departamento de Geologia, Instituto de Geociências, Universidade Federal do Rio de Janeiro, Rio de Janeiro. 2012. 91p.

CASSETI, V. Geomorfologia. [S.I.]: [2005]. Disponível em: <http://www.funape.org.br/geomorfologia/>. Acesso em: 19 de março de 2017.

DER. Mapa Rodoviário do Estado de Minas Gerais. Escala 1:720. 000. 2017.

EARTH EXPLORER. Disponível em: https://earthexplorer.usgs.gov/ Acesso em: 25 de março de 2017.

FLORENZANO, T. G.. Cartografia. In: FLORENZANO, T. G. (Org.) Geomorfologia: conceitos e tecnologias atuais. São Paulo: Oficina de Textos, 2008. p 105-128.

GATTO, L. C. S.; RAMOS, V. L. S.; NUNES, B. T. A.; MAMADE, L..Geomorfologia. In Projeto RADAMBRASIL. Ministério das Minas e Energia. Secretária Geral, 1983.

IBGE. Manual técnico da vegetação do Brasil. $2^{\circ}$ ed. Rio de janeiro: Instituto Brasileiro de Geografia e Estatística. 2012. 272p.

INSTITUTO MINEIRO DE GESTÃO DE ÁGUAS. IGAM. Disponível em: http://www.igam.mg.gov.br/ acessado em abril de 2017.

LOJA IBGE. Disponível em: http://loja.ibge.gov.br/. Acesso em: 25 de março de 2017.

MARQUES NETO, R., ZAIDAN, R. T., MENON JUNIOR, W. 2015. Mapeamento Geomorfológico do Município de Lima Duarte (MG). Revista Brasileira de Geomorfologia, v. 16, n¹, 2015, p 123-136. https://doi.org/10.20502/rbg.v16i1.641

MORALES, N. Evolução tectônica do Cinturão de Cisalhamento Campo do Meio na sua porção ocidental. Tese (Doutorado em Geociências) - Instituto de Geociências e Ciências Exatas, Universidade Estadual Paulista, Rio Claro, 1993. 220 p.

NUNES, B.A; RIBEIRO, M.I.C; ALMEIDA, V.J. NATALI FILHO T. Manual Técnico de Geomorfologia. Rio de Janeiro: IBGE (Série Manuais Técnicos em Geociências, n.5), 1994.113 p.

Plano Diretor Participativo do Município de Campos Gerais - MG. Campos Gerais: UFMG, 2007.

ROSS, J. L. S. - O registro cartográfico dos fatos Geomórficos e a questão da taxonomia do relevo. Revista do Departamento de Geografia. FFLCH-USP, n. - 6, 1992, p 17-29. https://doi.org/10.7154/RDG.1992.0006.0002

; MOROZ, I. C. Mapa geomorfológico do Estado de São Paulo: escala 1:500.000.

SISTEMA PARA O MONITORAMENTO AGRO-ENERGÉTICO DA CULTURA DO CAFÉ. SISMET. Disponível em: http://sismet.cooxupe.com.br:9000/ acessado em janeiro de 2019.

TRICART, J Principés et méthods de la géomorphologie. Mason: Paris, 1965. $496 \mathrm{p}$. https://doi.org/10.1097/00010694-196510000-00015

Recebido em: 24/04/2020

Aceito para publicação em: 26/06/2020 